\title{
Determination of the mode of reproduction of bahiagrass hybrids using cytoembryological analysis and molecular markers
}

\author{
Roberto Luis Weiler ${ }^{1 *}$, Miguel Dall'Agnol ${ }^{1}$, Carine Simioni ${ }^{1}$, Karine Cristina Krycki ${ }^{2}$, Nair \\ Dahmer $^{3}$, Divanilde Guerra ${ }^{4}$
}

\author{
${ }^{1}$ Universidade Federal do Rio Grande do Sul, Faculdade de Agronomia, Departamento de Plantas Forrageiras e Agrometeorologia, Porto Alegre, \\ RS, Brazil. \\ ${ }^{2}$ Universidade Federal do Rio Grande do Sul, Programa de Pós-graduação em Zootecnia, Porto Alegre, RS, Brazil. \\ ${ }^{3}$ Sociedade Educacional Três de Maio, Três de Maio, RS, Brazil. \\ ${ }^{4}$ Universidade Estadual do Rio Grande do Sul, Três Passos, RS, Brazil.
}

\begin{abstract}
The aim of this study was to determine the mode of reproduction of a hybrid progeny derived from intraspecific crosses of Paspalum notatum through cytoembryological analysis and use of RAPD (random amplification of polymorphic DNA) molecular markers. Cytoembryological analysis allowed identification of the mode of reproduction of 28 plants that were selected after agronomic productivity evaluations. Of these, 19 had embryo sac morphology compatible with an apomictic mode of reproduction and nine had embryo sac morphology compatible with a sexual mode of reproduction. Meanwhile, molecular marker analysis for 194 individuals showed 54 sexual and 140 apomictic plants; of the 28 plants analyzed by the two methods, ten results $(35.7 \%)$ were in disagreement. In this paper, through cytoembryological analyses, a ratio of 1:2.1 of sexual to apomictic plants was found. The BCU 243 marker showed a stable pattern of amplification, but some results differed with cytoembryological analyses, demonstrating that these analyses are more reliable when determining the mode of sexual reproduction for the plants of $P$. notatum. Apomictic plants characterized in this work can be tested in the field to check their agronomic value and registration as plant varieties, while the sexual plants can be used as potential parents in future crosses.
\end{abstract}

Key Words: apomixis, molecular analysis, Paspalum notatum, plant breeding, RAPD

\section{Introduction}

Animal production based on native pastures figures prominently in the state of Rio Grande do Sul, where it represents the dietary basis for this livestock. The Pampa biome has a great diversity of plant taxa, with about 400 species of grasses and 150 species of legumes (Boldrini, 1997).

Among the grasses native to Brazil, the genus Paspalum L. is representative of various herbaceous ecosystems and is responsible for producing a large portion of the available forage; thus it is an important tool used for the production of beef cattle (Valls, 1980). In the genus Paspalum, there is a close correlation between ploidy level and mode of reproduction, in which diploidy is correlated

Received: March 18, 2016

Accepted: October 27, 2016

*Corresponding author: robertoluisw@yahoo.com.br

http://dx.doi.org/10.1590/S1806-92902017000300002

How to cite: Weiler, R. L.; Dall'Agnol, M.; Simioni, C.; Krycki, K. C.; Dahmer, N. and Guerra, D. 2017. Determination of the mode of reproduction of bahiagrass hybrids using cytoembryological analysis and molecular markers. Revista Brasileira de Zootecnia 46(3):185-191

Copyright (C) 2017 Sociedade Brasileira de Zootecnia. This is an Open Access article distributed under the terms of the Creative Commons Attribution License (http://creativecommons.org/licenses/by/4.0/), which permits unrestricted use, distribution, and reproduction in any medium, provided the original work is properly cited. with sexual reproduction and outcrossing and polyploidy is correlated with apomixis (Adamowski et al., 2005).

The native germplasm of Paspalum notatum Flüggé is tetraploid and shows characteristics of apomictic lineages. In the ecotypes of $P$. notatum that have an apomictic mode of reproduction, female meiosis does not occur or is not functional. In "bahiagrass", apomixis is aposporic and pseudogamous, in which embryo sac arises by mitotic division of a somatic cell of the embryo sac and endosperm develops by the union of a male nucleus of the pollen grain with the polar nuclei (Acuña et al., 2009).

In crosses between apomictic and sexual plants, there is a wide segregation between plants of the two modes of reproduction. The most reliable way to assess whether an individual plant is apomictic or sexual is through cytoembryological analysis of the sexual embryo sacs and apomictic embryo sacs. Another way to evaluate the mode of reproduction is through the use of molecular markers, which requires a marker linked or at least very close to the gene region that controls the apomixis. In P. notatum, two RAPD (random amplification of polymorphic DNA) molecular markers were selected, completely linked to the expression of apospory: BCU 243 and BCU 259 (Martínez et al., 2003). The use of molecular markers allows rapid 
determination of the mode of reproduction at the seedling stage, enabling a screening of plants that will be taken to the field.

The objective of this study was to determine the mode of reproduction of a hybrid progeny derived from intraspecific crosses of $P$. notatum through cytoembryological analysis and through the use of RAPD molecular markers.

\section{Material and Methods}

In collaboration with IBONE (Instituto de Botânica del Nordeste), located in Corrientes, Argentina, three genotypes artificially polyploidizated by colchicine were obtained, called Q4188, Q4205 (Quarin et al. 2003), and C44X (Quarin et al., 2001). These three genotypes are sexual tetraploids and were used as female parents in artificial crosses with elite $100 \%$ apomictic tetraploid genotypes native from Rio Grande do Sul (ecotypes André da Rocha and Bagual), used as the male parents. The crosses were performed using the methodology described by Burton (1948) to obtain an F1 hybrid progeny. Crossing schemes allowed six combinations of parents that gave rise to the families Q4188 × André da Rocha (Progeny A), Q4188 × Bagual (Progeny B), Q4205 × André da Rocha (Progeny C), Q4205 $\times$ Bagual (Progeny D), C44X $\times$ André da Rocha (Progeny E), and C44X $\times$ Bagual (Progeny F).

The determination of the mode of reproduction through cytoembryological analysis was performed on 28 hybrids, selected from 196 evaluated for their dry mass productivity. To confirm their reproductive mode, cytoembryological analyses were also performed in all the parents involved in the crosses and the cultivar Pensacola of $P$. notatum, used as a control in all agronomic evaluations performed in hybrid progeny.

For the cytoembryological analysis, the inflorescences in anthesis (when the embryo sac is fully developed) were collected and the dissected flowers were fixed in FAA $(95 \%$ ethanol, $40 \mathrm{~mL}$; distilled water, $14 \mathrm{~mL} ; 40 \%$ formalin, $3 \mathrm{~mL}$; and Glacial acetic acid, $3 \mathrm{~mL}$ ) for $24 \mathrm{~h}$ at room temperature. After this period, they were stored in $70 \%$ ethanol and kept refrigerated until the extraction of ovaries that were dissected from the flowers. The samples containing the ovaries underwent a clarifying process consisting of a series of dehydrations in alcohol with methyl salicylate, following the protocol proposed by Young et al. (1979) and modified by Acuña et al. (2007).

Clarified ovaries were stored in a solution of methyl salicylate $(100 \%)$ until the interferential contrast microscopy analyses. For this, they were arranged on a slide and kept moist with methyl salicylate. For each hybrid plant, a minimum of 30 ovaries were analyzed to determine the mode of reproduction.

Single embryo sacs containing the egg apparatus, the binucleated central cell, and a mass of antipodals at the chalazal end were classified as sexual. In contrast, multiple or single embryo sacs with the egg apparatus, the central cell, and no antipodals were classified as apomictic. Plants producing ovules with either sexual or apomictic embryo sacs were classified as facultative (Acuña et al., 2007).

Of the hybrid plants resulting from crosses made, 194 (including the 28 individuals studied by cytoembryological analysis) were evaluated for their mode of reproduction using RAPD molecular markers. Extraction of DNA was performed according to the methodology described by Ferreira and Grattapaglia (1998), with the modification of making a microextraction of about $1 \mathrm{~cm}^{2}$ of a young leaf, ignoring the midrib. The DNA samples were quantified by electrophoresis ( $100 \mathrm{~V}$ for $1 \mathrm{~h}$ ) in $1 \%$ agarose gel, stained with ethidium bromide for visualization of bands, and compared with standards of known concentration $(50,100$, 200, and 500 ng DNA).

The polymerase chain reactions (PCR) were performed in a final volume of $13 \mu \mathrm{L}$ containing 1.5 units Taq polymerase, $10 \mathrm{mmol} \mathrm{L}^{-1}$ dNTP mix (dATP, dTTP, dCTP, dGTP), $2.5 \mu \mathrm{L} 10 \mathrm{x}$ buffer $\left(10 \mathrm{mmol} \mathrm{L}^{-1}\right.$ Tris - $\mathrm{HCl}(\mathrm{pH}$ 8.3), $50 \mathrm{mmol} \mathrm{L}^{-1} \mathrm{MgCl}, 30 \mathrm{pg}$ of each primer, $20 \mathrm{ng}$ of genomic DNA, and autoclaved water and amplified in MJ thermocycler. Visualization was done on $1.8 \%$ agarose gel prepared with TAE buffer $(0.04 \mathrm{M}$ Tris acetate, $1 \mathrm{mM}$ EDTA) at 100 volts for $3 \mathrm{~h}$ in horizontal wells.

The analysis of the gels was made by comparison of banding patterns between hybrids and the banding pattern of the parents (female and male), repeating the analysis of gel bands that were doubtful or not very clear.

\section{Results and Discussion}

Cytoembryological analyses allowed for the identification of the reproductive mode of 28 hybrid plants (Table 1) that were selected after agronomic evaluations of productivity (Weiler, 2013). The mode of reproduction of all 28 plants was successfully determined; 19 showed the morphology of the embryo sac compatible with apomictic reproduction (Figure 1) and nine had morphology of the embryo sac compatible with sexual reproduction (Figure 2). Two hybrid plants, A16 and B26, demonstrated facultative apomictic characteristics.

During the aposporic development, the megaspore mother cell can degenerate before or after the initial differentiation of apospory or suffer meiosis and form 
a reduced embryo sac. Thus, the sexual process can coexist with unreduced embryo sacs, becoming initially aposporic in one embryo sac (Karasawa, 2009) and aposporic apomictic plants may also exhibit some sexual reproduction at different frequencies and are, therefore, characterized as facultative apomictic plants. In these cases, a number of factors, such as seasonal fluctuations associated with photoperiod during development of the inflorescence and responses to day length, light intensity, temperature, and type and level of soil fertility, cause changes in the

Table 1 - Mode of reproduction of 28 selected hybrid plants obtained from intraspecific crosses of Paspalum notatum, determined by cytoembryological analyses

\begin{tabular}{|c|c|c|c|c|c|c|c|}
\hline Genotypes & Sexual ovaries & Apomictic ovaries & Atrophied ovaries & Sterile ovaries & Abnormal ovaries & Total ovaries & Mode of reproduction \\
\hline D3 & - & 24 & - & - & 18 & 42 & Apomictic \\
\hline $\mathrm{C} 17$ & - & 22 & - & - & 18 & 40 & Apomictic \\
\hline D16 & 30 & - & - & - & 8 & 38 & Sexual \\
\hline B17 & 7 & 1 & - & 1 & 97 & 106 & Apomictic \\
\hline $\mathrm{C} 2$ & 1 & 21 & - & 2 & 14 & 38 & Apomictic \\
\hline B43 & - & 41 & 3 & - & 1 & 45 & Apomictic \\
\hline $\mathrm{C} 24$ & 17 & - & 3 & - & 14 & 34 & Sexual \\
\hline $\mathrm{D} 25$ & 23 & - & - & - & 8 & 31 & Sexual \\
\hline $\mathrm{C} 18$ & 24 & - & - & 1 & 16 & 41 & Sexual \\
\hline F15 & - & 40 & - & - & - & 40 & Apomictic \\
\hline F29 & 2 & 26 & - & - & 10 & 38 & Apomictic \\
\hline B26 & 26 & 16 & - & - & 14 & 56 & Apomictic facultative \\
\hline B37 & - & 31 & - & - & 7 & 38 & Apomictic \\
\hline F24 & - & 29 & - & - & 10 & 39 & Apomictic \\
\hline D17 & 28 & - & 4 & - & 24 & 56 & Sexual \\
\hline $\mathrm{C} 32$ & 4 & - & - & - & 26 & 30 & Sexual \\
\hline C9 & 2 & 3 & - & - & 28 & 33 & Apomictic \\
\hline C6 & - & 21 & - & - & 9 & 30 & Apomictic \\
\hline $\mathrm{C} 15$ & - & 29 & - & 1 & 1 & 31 & Apomictic \\
\hline B29 & 2 & - & - & - & 28 & 30 & Apomictic \\
\hline D23 & 23 & - & - & - & 17 & 40 & Sexual \\
\hline B35 & 26 & - & - & 7 & 12 & 45 & Apomictic \\
\hline A 20 & 2 & 34 & 1 & - & 3 & 40 & Apomictic \\
\hline $\mathrm{C} 22$ & - & 24 & - & 1 & 6 & 31 & Apomictic \\
\hline A 16 & 12 & 19 & - & - & 33 & 64 & Apomictic facultative \\
\hline $\mathrm{C} 23$ & - & 27 & 2 & - & 10 & 39 & Apomictic \\
\hline B2 & 4 & 1 & - & - & 26 & 31 & Sexual \\
\hline B28 & 24 & - & - & - & 16 & 40 & Sexual \\
\hline Bagual & - & 28 & - & 1 & 9 & 38 & Apomictic \\
\hline André da Rocha & - & 22 & 1 & 1 & 14 & 38 & Apomictic \\
\hline Pensacola & 19 & - & 2 & 3 & 12 & 36 & Sexual \\
\hline
\end{tabular}

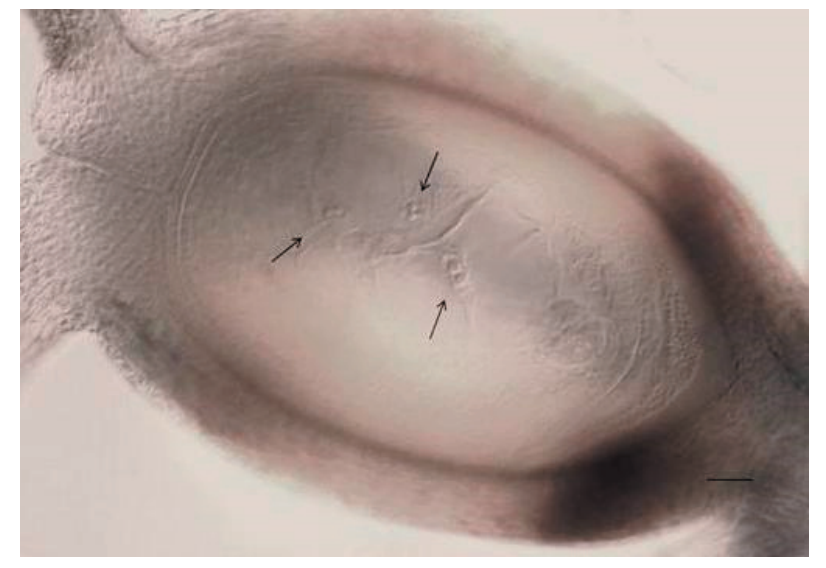

Arrows indicate multiple sacs. Scale bar: $10 \mu \mathrm{m}$.

Figure 1 - Morphology of the embryo sac in the apomictic hybrid B43.

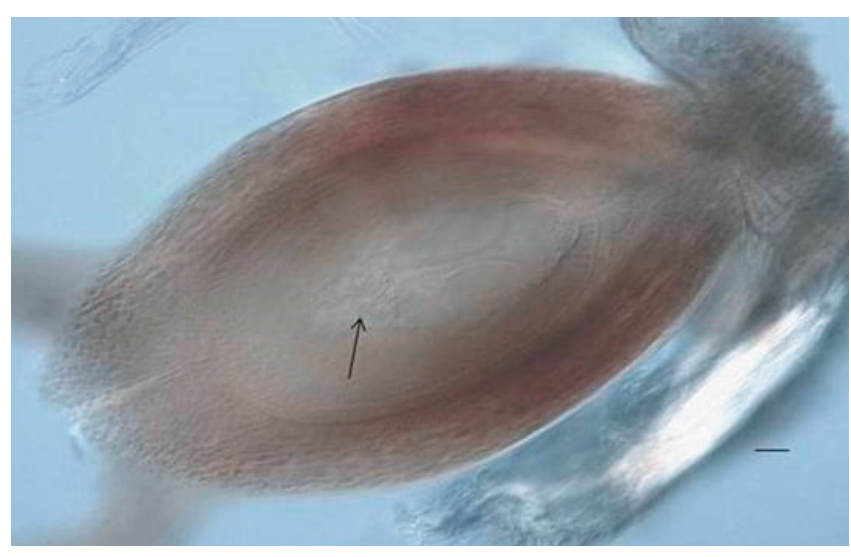

Arrow indicates the antipodes.

Scale bar: $10 \mu \mathrm{m}$.

Figure 2 - Morphological features of the embryo sac of the sexual hybrid plant B37. 
frequency of incidences of sexual and apomictic embryos (Koltunow, 1993).

The genetic control of apomixis in tetraploid $P$. notatum is by a single dominant locus and with Mendelian segregation, but in controlling the expression of apomixis, there is probably a pleiotropic lethal effect of the dominant locus or partial lethality factors linked to the aposporic gene, possibly causing segregation distortion in favor of plants with the sexual mode of reproduction (Martínez et al., 2001).

Valle and Savidan (1996) reported that the occurrence of two types of sacs in the same embryonic egg in apomictic plants of Brachiaria is considered indicative of facultative apomixis. Quarin et al. (2001) also mentioned that an artificially induced tetraploid population may have apomictic, sexual, or facultative mode of reproduction, indicating that apomictic genes exist in diploid plants and that expression of these genes is repressed in the diploid level.

In Brachiaria, it was found that the sexual embryo sac present in facultative apomictic plants can be fertilized, form a zygote, and generate a plant sexually, thus characterizing facultative apomixis that, by definition, is the occurrence of viable seeds derived from fertilization of a sexual embryo sac in a apomictic plant (Nogler, 1984; Koltunow, 1993). In this genus, the frequency of embryo sacs with reduced apospory can vary from 0 to $50 \%$ (Valle et al., 1994).

A high number of abnormal ovaries were found in almost all plants (Table 1), ratio of 1:2.4 (abnormal:total ovaries), possibly because the ovaries were not in the best period of anthesis when inflorescences were collected for analysis.

In this paper, 28 plants were selected for the cytoembryological analysis, because these plants had the largest dry mass production; a ratio of 1:2.1 was found (sexual:apomictic), which did not differ $(\mathrm{P}>0.05)$ from the expected ratio of 1:3 (sexual:apomictic). The genetic aposporic segregation was previously explained by a genetic model of simple Mendelian inheritance with dominance of apospory over sexual reproduction, but with a strong distortion of segregation (Martínez et al., 2001). Contrary to that found in this study, Fortes et al. (2004) mentioned that this distortion had been found responsible for values of 4.3:1 (sexual:apomictic), differing from the expected 1:1. Martínez et al. (2001) found values of 2.8:1 (sexual: apomictic), while the work of Stein et al. (2004) found 6.5:1 (sexual:apomictic). All these studies were conducted with Paspalum notatum genotypes.

The analyses with molecular markers showed that only the primer BCU 243 had a stable pattern of band amplification in ten different reactions with the female parents (Q4188, Q4205 and C44X), the male parents (Bagual and André da Rocha), and the cultivar Pensacola. In sexual plants, a band of $700 \mathrm{bp}$ was found and for apomictic plants, two bands were found, one at $700 \mathrm{bp}$ and the other at 750 bp (Figure 3). Primer BCU 259 showed no stable pattern of differentiation of apomictic and sexual plants when parents were tested. The work of Martínez et al. (2003) showed that the BCU 243 primer amplified a fragment specific to apomictic parents in bulk analysis.

The ratio of 1:2.6 (sexual plants:apomictic) was found; however, in studies conducted at IBONE, evaluating 44 hybrids, Martínez et al. (2001) found a ratio of 4.5:1 (sexual:apomictic). This distorted segregation is possibly related to the lethal effect of the dominant pleiotropic locus or partial lethality factors linked to the aposporic gene.

The findings of the molecular marker analysis in this study were somewhat similar to the expected, with 54 sexual plants to 140 apomictic plants (Table 2), meaning a ratio similar to the expected of 1:2.6 (sexual:apomictic).

In progeny $\mathrm{A}$, of the 29 hybrids obtained, 21 were considered apomictic and eight were sexual. In progeny B, of 44 hybrids, 27 were apomictic and 17 were sexual. In progeny $\mathrm{C}$, of 37 hybrids, 30 were apomictic and seven were sexual. In progeny D, of 27 hybrids, 20 were apomictic and seven were sexual. In progeny $\mathrm{E}$, of 24 hybrids, 15 were apomictic and nine were sexual. In progeny F, of 33 hybrids, 27 were apomictic and six were sexual (Table 2). In all progenies, fewer sexual hybrids were found in comparison with apomictic, ranging from a ratio of 1:1.4 (sexual: apomictic) in family $\mathrm{E}$ to a ratio of 1:4.5 (sexual:apomictic) in family F.

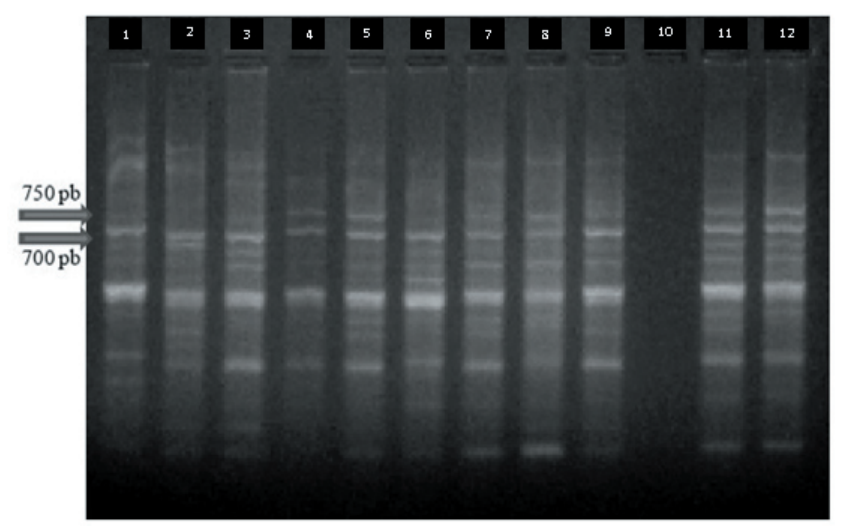

Indicated bands are 700 and $750 \mathrm{bp}$.

Figure 3 - Agarose gel at $1.8 \%$ with the sexual female parents Q4188, Q4205, and C44X (columns 1, 2, and 3), apomictic male parents André da Rocha and Bagual (columns 4 and 5), Pensacola (column 6), hybrids A24, A25, A26, A28, A29 (columns 7, 8, 9, 11, and 12), and column 10 , a fail amplification. 
The cytoembryological analysis is made with direct visualization of the ovaries and the determination of the mode of reproduction occurs through the structures observed. Many ovaries of different flowers and inflorescences are measured, resulting in higher reliability.

Of the 28 plants analyzed by the two methods, ten results $(35.7 \%)$ were in disagreement. They were plants A16, B17, B28, B37, C24, C32, D16, D17, D23, and D25. Possibly, the variance of the results can be attributed to the marker used; even if this marker worked in the IBONE studies, it did not show satisfactory repeatability of the results. According to Meunier and Grimont (1993), the low reproducibility of RAPD could be explained by the low touchdown of primers $\left(\sim 30^{\circ} \mathrm{C}\right)$. Thus, the annealing was done at a higher touchdown temperature $\left(35^{\circ} \mathrm{C}\right)$, which gave higher stringency conditions for good day-to-day reproducibility. However, the data shown by Fortes et al. (2004), after analyzing 44 hybrids using RAPD markers,

Table 2 - Mode of reproduction of intraspecific hybrid progeny of Paspalum notatum, determined by BCU 243 RAPD molecular marker

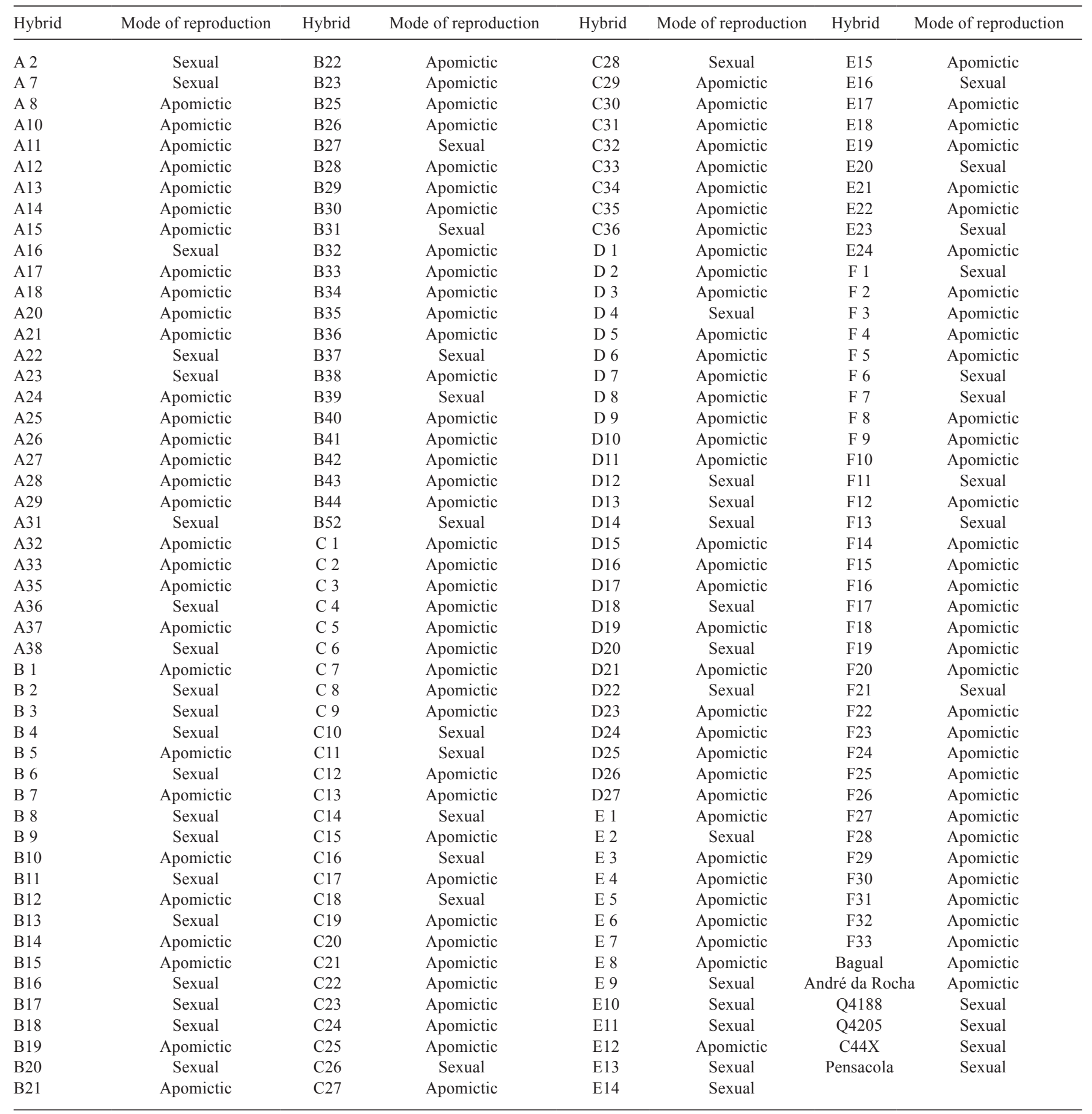


showed similar results to the cytoembryological analysis, finding more apomictic than sexual plants.

Rebozzio et al. (2012), using RAPD markers BCU 243 and BCU 259 along with eleven AFLP markers, showed that these markers, previously connected to the aposporic region in the apomictic plant Q4117, were also conserved in other apomictic accessions, although the marker of the BCU 243 primer in particular presented a band clearly linked to the aposporic region. According to the same authors, in an attempt to obtain SCAR (sequencecharacterized amplified regions) markers, which would be more specific in the identification of apomictic plants, it was only possible to develop a SCAR marker from an AFLP (amplified fragment length polymorphism) marker (Espinoza et al., 2006).

Molecular markers can be a useful tool in distinguishing sexual and apomictic plants by accelerating the process of identification and selection of apomictic plants. However, results must be validated for each laboratory by comparison with embryological data. As a result, the repetition of the molecular analyses, including other markers, should be performed.

For all the parents involved in the crosses and the cultivar Pensacola of $P$. notatum, the mode of reproduction was confirmed by both analyses.

In a breeding program, it is essential to determine the mode of reproduction in segregating progenies obtained by crosses between sexual and apomictic genotypes, allowing the formation of groups of plants separated by the mode of reproduction. Thus, apomictic plants can be used directly as cultivars if they are of agronomic interest, while sexual plants can be inserted as female parents in programs of continued crosses.

The data obtained in this work represent a major breakthrough for the breeding program. This makes it possible to directly use selected plants by their agronomic performance, subjecting apomictic plants to new field trials to prove their agronomic value and also allow the registration and protection of plant varieties. Besides, sexual plants could be used for future crosses, making them potential parents within this program.

\section{Conclusions}

The predominant mode of reproduction is the apomictic in a ratio of 1:2.1 of sexual to apomictic plants.

It is possible to determine the mode of reproduction through cytoembryological and RAPD molecular marker analyses.

\section{Acknowledgments}

The authors thank Conselho Nacional de Desenvolvimento Científico e Tecnológico (CNPq) for the financial support.

\section{References}

Acuña, C. A.; Blount, A. R.; Quesenberry, K. H.; Hanna, W. W. and Kenworthy, K. E. 2007. Reproductive characterization of bahiagrass germplasm. Crop Science 47:1711-1717. doi: http:// dx.doi.org/10.2135/cropsci2006.08.0544.

Acuña. C. A.; Blount, A. R.; Quesenberry, K. H.; Kenworthy, K. E. and Hanna, W. W. 2009. Bahiagrass tetraploid germoplasm: reproductive and agronomic characterization of segregating progeny. Crop Science 49:581-588. doi: http://dx.doi.org/10.2135/ cropsci2008.07.0402.

Adamowski, E. V.; Pagliarini, M. S.; Mendes-Bonato, A. B.; Batista, L. A. R. and Valls, J. F. M. 2005. Chromosome numbers and meiotic behavior of some Paspalum accessions. Genetic and Molecular Biology 28:773-780. doi: http://dx.doi.org/10.1590/ S1415-47572005000500020.

Boldrini, I. I. 1997. Campos do Rio Grande do Sul: caracterização fisionômica e problemática ocupacional. S.L, UFRGS.

Burton, G. W. 1948. Artificial fog chamber facilitates Paspalum emasculation. Journal America Society Agronomy 40:281-282.

Espinoza, F.; Daurelio, L. D.; Pessimo, S. C.; Valle, E. M. and Quarin, C. L. 2006. Genetic characterization of Paspalum notatum accessions by AFLP markers. Plant Systematics and Evolution 258:147-159. doi: http://dx.doi.org/10.1007/s00606-005-0401-x.

Ferreira, M. E. and Grattapaglia, D. 1998. Introdução ao uso de marcadores moleculares em análise genética. Embrapa, Brasília.

Fortes, N. B.; Tcach, M.; Acuña, C. A.; Martínez, E. J. and Quarin, C. L. 2004. Segregación de la apomixis in Paspalum notatum a partir de cruzamientos entre uns planta sexual autotetraploide induzida y um padre apomíctico. Comunicaciones Científicas y Tecnológicas A-008.

Karasawa, M. M. G. 2009. Diversidade reprodutiva de plantas. Sociedade Brasileira de Genética, Ribeirão Preto, SP.

Koltunow, A. M. 1993. Apomixis: Embryo sacs and embryos formed without meiosis or fertilization in ovules. The Plant Cell 5:1425-1437. doi: http://dx.doi.org/10.1105/tpc.5.10.1425.

Martínez, E. J.; Urbani, M. H.; Quarin, C. L. and Ortiz, J. P. A. 2001. Inheritance of apospoy in bahiagrass, Paspalum notatum. Hereditas 135:19-25. doi: http://dx.doi.org/10.1111/j.16015223.2001.00019.x.

Martínez, E. J.; Hoop, H. E.; Stein, J.; Ortiz, J. P. A. and Quarin, C. L. 2003. Genetic characterization of apospory in tetraploid Paspalum notatum based on the identification of linked molecular markers. Molecular Breeding 12:319-327. doi: http://dx.doi.org/10.1023/B: MOLB.0000006868.12568.32.

Meunier, J. R. and Grimont, P. A. D. 1993. Factors affecting reproducibility of random amplified polymorphic DNA fingerprinting. Research in Microbiology 144:373-379. doi: http://dx.doi.org/10.1016/0923-2508(93)90194-7.

Nogler, G. A. 1984. Genetics of apospory in apomictic Ranunculus auricomus. V. Conclusion. Botanica Helvetica 94:411-422.

Quarin, C. L.; Espinoza, F.; Martinez, E. J.; Pessino, S. C. and Bovo, O. A. 2001. A rise of ploidy level induces the expression of apomixis in Paspalum notatum. Sexual Plant Reproduction 13:243-249. doi: http://dx.doi.org/10.1007/s004970100070.

Quarin, C. L.; Urbani, N. H.; Blount, A. R.; Mertínez, E. J.; Hack, C. M.; Burton, G. W. and Quesenberry, K. H. 2003. Registration 
of Q4188 and Q4205, sexual tetraploid germplasm lines of bahiagrass. Crop Science 43:745-746.

Rebozzio, R. N.; Rodríguez, M. P.; Stein, J.; Ortiz, J. P. A.; Quarin, C. L. and Espinoza, F. 2012. Validation of molecular markers linked to apospory in tetraploid races of bahiagrass, Paspalum notatum Flügge. Molecular Breeding 29:189-198. doi: http://dx.doi.org/ 10.1007/s11032-010-9537-7.

Stein, J.; Quarin, C. L.; Martínez, E. J.; Pessino, S. C. and Ortiz, J. P. A. 2004. Tetraploid races of Paspalum notatum show polysomic inheritance and preferential chromosome pairing around the apospory-controlling locus. Theoretical and Applied Genetics 109:186-191. doi: http://dx.doi.org/10.1007/s00122-004-1614-z.

Valle, C. B.; Glienke, C. and Leguizamon, G. O. C. 1994. Inheritance of apomixis in Brachiaria, a tropical forage grass. Apomixis Newsletter 7:42-43.
Valle, C. B. and Savidan, Y. H. 1996. Genetics, cytogenetics and reproductive biology of Brachiaria. p.147-163. In: Brachiaria: Biology, agronomy and improvement. Miles, J. W.; Maass, B. L. and C. B. Valle, eds. EMBRAPA-CNPGC, Brasília.

Valls, J. F. M. 1980. Gramíneas nativas e sua importância forrageira: situação do estudo no país. p.7-23. In: Plantas forrageiras. Empresa Brasileira de Pesquisa Agropecuária. Centro Nacional de Recursos Genéticos, Brasília.

Weiler, R. L. 2013. Hibridação intraespecífica, determinação do modo de reprodução e duplicação cromossômica de Paspalum notatum Flügge. Tese (D.Sc.). Universidade Federal do Rio Grande do Sul, Faculdade de Agronomia, Porto Alegre.

Young, B. A.; Sherwood, R. T. and Bashaw, E. C. 1979. Cleared-pistil and thick-sectioning techniques for detecting aposporous apomixis in grasses. Canadian Journal of Botany 57:1668-1672. 